\title{
Synthesis of two new Mo(II) organometallic catalysts immobilized on POSS for application in olefin oxidation reactions
}

\author{
Eduardo Guimarães Vieira ${ }^{\mathrm{a},}{ }^{*}$, Alexandre Gonçalves Dal-Bó ${ }^{\mathrm{b}}$, Tiago Elias Allievi Frizon ${ }^{\mathrm{b}}$, \\ Newton Luiz Dias Filho ${ }^{\text {a, }}$ b, *** \\ a Departamento de Física e Química, Unesp-Univ Estadual Paulista, Av. Brasil, 56-Centro, Caixa Postal 31, 15385-000 Ilha Solteira, São Paulo, Brazil \\ ${ }^{\mathrm{b}}$ Universidade do Extremo Sul Catarinense, Av. Universitária, 1105, CP 3167, CEP 88806-000, Criciúma, Santa Catarina, Brazil
}

\section{A R T I C L E I N F O}

\section{Article history:}

Received 22 November 2016

Received in revised form

31 January 2017

Accepted 9 February 2017

Available online 11 February 2017

\section{Keywords:}

Molybdenum complexes

Modified silsesquioxane

Catalysts

Epoxidation of olefins

\begin{abstract}
A B S T R A C T
The purpose of this work was the preparation and characterization of two new catalysts POSS-ATZAc$\left[\mathrm{Mo}\left(\eta^{3}-\mathrm{C}_{3} \mathrm{H}_{5}\right) \mathrm{Br}(\mathrm{CO})_{2}\right]$ (POSS-Mo-I) and POSS-ATZAc-[Mo(CO) $\left.{ }_{3} \mathrm{Br}_{2}\right]$ (POSS-Mo-II). The new heterogeneous catalysts were characterized by several techniques and used as catalysts for the epoxidation of olefins, presenting high catalytic activity. To study and optimize the syntheses of the heterogeneous catalysts, immobilization experiments of the $\left[\mathrm{Mo}\left(\eta^{3}-\mathrm{C}_{3} \mathrm{H}_{5}\right) \mathrm{Br}(\mathrm{CO})_{2}(\mathrm{NCMe})_{2}\right]$ and $\left[\mathrm{Mo}(\mathrm{CO})_{3} \mathrm{Br}_{2}(\mathrm{NCMe})_{2}\right]$ organometallic complexes on the modified polyhedral oligomeric silsesquioxane were performed. The sorption properties of the modified silsesquioxane showed to be dependent of the contact time, concentration and temperature. Catalysts were tested in the epoxidation of six olefins and compared with homogeneous species $\left[\mathrm{Mo}\left(\eta^{3}-\mathrm{C}_{3} \mathrm{H}_{5}\right) \mathrm{Br}(\mathrm{CO})_{2}(\mathrm{ATZAc})\right](\mathrm{Mo}-\mathrm{I})$ and $\left[\mathrm{Mo}(\mathrm{CO})_{3} \mathrm{Br}_{2}(\mathrm{ATZAC})\right]$ (Mo-II). To the best of our knowledge, this paper is the first that has reported the preparation and characterization of two new heterogeneous catalysts, as well as the comparison with homogeneous species for catalytic epoxidation of olefins.
\end{abstract}

(c) 2017 Elsevier B.V. All rights reserved.

\section{Introduction}

Organometallic complexes can catalyse many reactions and are highly used in industrial processes [1]. Molybdenum(II) complexes have been used to synthesize effective catalysts for the epoxidation of olefins using tert-butyl hydroperoxide (TBHP) as oxidant, a process which starts with the oxidation of the precursor complex to an active species of molybdenum (VI) [2]. Attention in molybdenum complexes arises primarily from their use as (pre)catalysts or starting material for various organic transformations. One problem of the homogeneous catalysts is the difficulty of separating, recovering and recycling the catalyst.

In recent years, the demand for heterogeneous catalysts with high catalytic activity and selectivity has been increasing rapidly. Research in this area can still be considered incipient when we take into account the different combinations of chemical species to form

\footnotetext{
* Corresponding author.

** Corresponding author. Universidade do Extremo Sul Catarinense, Av. Universitária, 1105, CP 3167, CEP 88806-000, Criciúma, Santa Catarina, Brazil.

E-mail addresses: eduardogv5007@gmail.com (E.G. Vieira), nldias@unesc.net (N.L. Dias Filho).
}

another with new properties. To obtain a great heterogeneous catalyst, it is necessary to choose a suitable support which has specific properties such as thermal and mechanical stability as well as prevent loss of the catalyst. A lot of attention has recently been given to the synthesis of organic-inorganic hybrid silsesquioxane with eight pendant organic molecular "arms", which are known as polyhedral oligomer silsesquioxane (POSS). In the POSS, the cubic core is rigid with diameter $0.53 \mathrm{~nm}$ and a spherical radius of $1-3 \mathrm{~nm}$ including peripheral organic units [3].

However, to the best of our knowledge, this study is the first that has reported the preparation of a POSS functionalized with 3amino-1,2,4-triazole-5-carboxylic acid (ATZAc) and complexes of molybdenum (II) for catalytic epoxidation of olefins.

Therefore, the objective of this work is the synthesis of two new heterogeneous catalysts POSS-ATZAc-[ $\left.\mathrm{Mo}\left(\eta^{3}-\mathrm{C}_{3} \mathrm{H}_{5}\right) \mathrm{Br}(\mathrm{CO})_{2}\right]$ (POSS-Mo-I) and POSS-ATZAc-[Mo(CO) $\left.{ }_{3} \mathrm{Br}_{2}\right]$ (POSS-Mo-II). POSSMo-I and POSS-Mo-II were tested as catalysts in the epoxidation of olefins and compared with the homogeneous catalysts $\left[\mathrm{Mo}\left(\eta^{3}-\right.\right.$ $\left.\left.\mathrm{C}_{3} \mathrm{H}_{5}\right) \mathrm{Br}(\mathrm{CO})_{2}(\mathrm{ATZAC})\right]$ (Mo-I) and [Mo(CO) ${ }_{3} \mathrm{Br}_{2}$ (ATZAC)] (Mo-II). 


\section{Preparations}

\subsection{Synthesis of POSS-PrCl}

3-Chloropropyltriethoxysilane (CPTES) (225 mL) was added to a stirred mixture of methanol (4 l) and concentrated hydrochloric acid $(135 \mathrm{~mL})$ under a slow continuous nitrogen purge. The reaction mixture was allowed to stir for six weeks. The resultant solution was then filtered and dried to give a white solid (POSS-PrCl) with $41 \%$ yield, according to our previous work [4]. Elemental Analysis for $\mathrm{Si}_{8} \mathrm{O}_{12} \mathrm{C}_{24} \mathrm{H}_{48} \mathrm{Cl}_{8}$ (1036.9 g/mol): calculated C $27.77 \%, \mathrm{H} 4.63 \%$; found C 27.56\%, H 4.42\%. IR ( KBr pellet, $\left.\mathrm{cm}^{-1}\right): \nu(\mathrm{C}-\mathrm{H})=2956, \nu(\mathrm{Si}-$ $\mathrm{C})=1627, v_{\mathrm{as}}(\mathrm{Si}-\mathrm{O}-\mathrm{Si})=1108, \nu(\mathrm{C}-\mathrm{Cl})=698 .{ }^{13} \mathrm{C}$ solid-state NMR (100.61 MHz, ppm): $10.76\left(\mathrm{CH}_{2}-\mathrm{Si}\right), 27.14\left(\mathrm{CH}_{2}-\mathrm{CH}_{2} \mathrm{Si}\right), 48.30\left(\mathrm{CH}_{2}-\right.$ Cl). ${ }^{29} \mathrm{Si}$ solid-state NMR (79.48 MHz, (Si-O), ppm): -68.50 (high intensity), -67.42 (low intensity). EDS (Full scale 52191 ct cursor: -0.268 (octs), keV): C, O, Si, Cl.

\subsection{Synthesis of POSS-ATZAC}

A solution of 3-amino-1,2,4-triazole-5-carboxylic acid (ATZAc) (49.41 g, $385.7 \mathrm{mmol}$ ) in anhydrous dimethylformamide $(300 \mathrm{~mL})$ was added over a period of $50 \mathrm{~min}$ to a stirred solution of POSS-PrCl (25 g, $24.11 \mathrm{mmol}$ ) in $300 \mathrm{~mL}$ of DMF. The temperature was allowed to rise to $160{ }^{\circ} \mathrm{C}$ and stirring was continued for $48 \mathrm{~h}$ resulting in a white solution. Ethanol was added to precipitate octa[3-amino1,2,4-triazole-5-carboxylic acid) propyl] silsesquioxane. The precipitate was separated by filtration and washed with ethanol resulting in the POSS-ATZAc, according to our previous work [4]. The resulting product was obtained after several attempts. Elemental Analysis for $\mathrm{Si}_{8} \mathrm{O}_{28} \mathrm{C}_{48} \mathrm{H}_{72} \mathrm{~N}_{32}$ (1768.8 g/mol): $\mathrm{C} 32.56 \%, \mathrm{~N}$ 25.32\%, H 4.07\%; found C 32.49\%, N 24.95\%, H 4.00\%. IR (KBr pellet, $\left.\mathrm{cm}^{-1}\right): \nu(\mathrm{C}-\mathrm{H})=2939, \nu(\mathrm{C}=\mathrm{O})=1704, \nu(\mathrm{C}=\mathrm{N})=1600, \nu(\mathrm{C}-$ $\mathrm{N})=1446, v_{\text {as }}(\mathrm{Si}-\mathrm{O}-\mathrm{Si})=1112 .{ }^{13} \mathrm{C}$ solid-state NMR $(100.61 \mathrm{MHz}$, ppm): $9.64 \quad\left(\mathrm{CH}_{2}-\mathrm{Si}\right), \quad 23.23 \quad\left(\mathrm{CH}_{2}-\mathrm{CH}_{2} \mathrm{Si}\right), \quad 48.95 \quad\left(\mathrm{CH}_{2}-\mathrm{N}\right)$, 140.66-149.40 (aromatic ring), 155.22 (carboxylic acid group). ${ }^{29} \mathrm{Si}$ solid-state NMR (79.48 MHz, (Si-O), ppm): -66.04 (high intensity), -58.04 (low intensity). EDS (Full scale 58029 ct cursor: -0.152 (octs), keV): C, N, O, Si.

\subsection{Synthesis of homogeneous species $\left[\mathrm{Mo}\left(\eta^{3}-\mathrm{C}_{3} \mathrm{H}_{5}\right)\right.$ $\left.\mathrm{Br}(\mathrm{CO})_{2}(\mathrm{ATZAC})\right](\mathrm{Mo}-\mathrm{I})$}

The organometallic complex $\left[\mathrm{Mo}\left(\eta^{3}-\mathrm{C}_{3} \mathrm{H}_{5}\right) \mathrm{Br}(\mathrm{CO})_{2}(\mathrm{NCMe})_{2}\right]$ was prepared according to literature methods [1,5]. A solution of $\left[\mathrm{Mo}\left(\eta^{3}-\mathrm{C}_{3} \mathrm{H}_{5}\right) \mathrm{Br}(\mathrm{CO})_{2}(\mathrm{NCMe})_{2}\right](2.0 \mathrm{~g}, 5.63 \mathrm{mmol})$ in ethanol $(60 \mathrm{~mL})$ was treated with 3-amino-1,2,4-triazole-5-carboxylic acid (ATZAc) $(0.72 \mathrm{~g}, 5.63 \mathrm{mmol})$. The resulting solution was stirred for $8 \mathrm{~h}$ under reflux and evaporated to dryness. The solid obtained was washed with hexane and dried under vacuum (1.98 g yield) [6]. Elemental Analysis for $\mathrm{MoC}_{9} \mathrm{O}_{2} \mathrm{BrN}_{2} \mathrm{H}_{11}$ (354.94 g/mol): calculated C 30.42\%, N 7.88\%, H 3.10\%, Mo 27.03\%; found C 30.28\%, N 7.82\%, H 2.98\%, Mo 26.95\%. IR ( $\mathrm{KBr}$ pellet, $\left.\mathrm{cm}^{-1}\right): \nu(\mathrm{C} \equiv \mathrm{O})=1943-1857, \nu$ $(\mathrm{C}=\mathrm{O})=1686$. EDS (Full scale 22153 ct cursor: -0.348 (octs), keV): C, N, O, Br, Mo.

\subsection{Synthesis of homogeneous species $\left[\mathrm{Mo}(\mathrm{CO}){ }_{3} \mathrm{Br}_{2}(\mathrm{ATZAC})\right](\mathrm{Mo}-$ II)}

The organometallic complex $\left[\mathrm{Mo}(\mathrm{CO})_{3} \mathrm{Br}_{2}(\mathrm{NCMe})_{2}\right]$ was prepared according to literature methods $[1,4,5]$. A solution of Mo-II $(2.3 \mathrm{~g}, 5.45 \mathrm{mmol})$ in ethanol $(60 \mathrm{~mL})$ was treated with 3-amino1,2,4-triazole-5-carboxylic acid (ATZAc) ( $0.70 \mathrm{~g}, 5.45 \mathrm{mmol}$ ). The resulting solution was stirred for $8 \mathrm{~h}$ under reflux and evaporated to dryness. The solid obtained was washed with hexane and dried under vacuum (2.22 g of yield) [6]. Elemental Analysis for $\mathrm{MoC}_{7} \mathrm{O}_{3} \mathrm{Br}_{2} \mathrm{~N}_{2} \mathrm{H}_{6}$ (421.94 g/mol): calculated C $19.90 \%, \mathrm{~N} \mathrm{6.63 \% ,} \mathrm{H}$ $1.42 \%$, Mo 22.73\%; found C $19.76 \%$, N 6.59\%, H 1.31\%, Mo $22.65 \%$. IR $\left(\mathrm{KBr}\right.$ pellet, $\left.\mathrm{cm}^{-1}\right): \nu(\mathrm{C} \equiv \mathrm{O})=1879,1974,204, \nu(\mathrm{C}=\mathrm{O})=1679$. EDS (Full scale 37854 ct cursor: -0.348 (octs), keV): C, N, O, Br, Mo.

\subsection{Synthesis of heterogeneous catalyst POSS-ATZAc- $\left[\mathrm{Mo}\left(\eta^{3}-\mathrm{C}_{3} \mathrm{H}_{5}\right)\right.$ $\left.\mathrm{Br}(\mathrm{CO})_{2}\right]$ (POSS-Mo-I)}

Octa[(3-amino-1,2,4-triazole-5-carboxylicacid)propyl] octasilsesquioxane, POSS-ATZAc $(2.5 \mathrm{~g}, 1.41 \mathrm{mmol})$ was added to a stirred solution of $\left[\mathrm{Mo}\left(\eta^{3}-\mathrm{C}_{3} \mathrm{H}_{5}\right) \mathrm{Br}(\mathrm{CO})_{2}(\mathrm{NCMe})_{2}\right](4.00 \mathrm{~g}$, $11.27 \mathrm{mmol})$ in anhydrous ethanol $(50 \mathrm{~mL})$ under nitrogen and the mixture was allowed to stir overnight at $80^{\circ} \mathrm{C}$. The solvent was removed by filtration; the solid that remained (yellow powder) was washed three times with anhydrous dichloromethane, and dried, giving $2.35 \mathrm{~g}$ of POSS-Mo-I. Elemental Analysis for $\mathrm{Si}_{8} \mathrm{O}_{36} \mathrm{C}_{68} \mathrm{H}_{92} \mathrm{~N}_{32} \mathrm{Br}_{4} \mathrm{Mo}_{4}$ (2859.36 g/mol): calculated C $28.53 \%, \mathrm{~N}$ 15.66\%, H 3.21\%, Mo 13.42\%; found C 28.32\%, N 15.19\%, H 3.02\%, Mo 13.15\%. IR (KBr pellet, $\left.\mathrm{cm}^{-1}\right): \nu(\mathrm{C}-\mathrm{H})=2927, \nu(\mathrm{C} \equiv \mathrm{O})=1938-1839$, $\nu(\mathrm{C}=\mathrm{O})=1656, \nu(\mathrm{C}=\mathrm{N})=1571, \nu(\mathrm{C}-\mathrm{N})=1450, v_{\text {as }}(\mathrm{Si}-\mathrm{O}-\mathrm{Si})=1110$. ${ }^{13} \mathrm{C}$ solid-state NMR (100.61 MHz, ppm): $8.60\left(\mathrm{CH}_{2}-\mathrm{Si}\right), 22.46\left(\mathrm{CH}_{2}-\right.$ $\mathrm{CH}_{2} \mathrm{Si}$ ), $47.51\left(\mathrm{CH}_{2}-\mathrm{N}\right), 139.93-148.93$ (aromatic ring), 154.53 (carboxylic acid group), 76.66, 83.92, 117.89 (allyl groups of complex). ${ }^{29} \mathrm{Si}$ solid-state NMR (79.48 MHz, (Si-O), ppm): -66.35 (high intensity), -57.14 (low intensity). EDS (Full scale $18840 \mathrm{ct}$ cursor: -0.256 (octs), keV): C, N, O, Br, Si, Mo.

\subsection{Synthesis of heterogeneous catalyst POSS-ATZAc- $\left[\mathrm{Mo}(\mathrm{CO})_{3} \mathrm{Br}_{2}\right]$ (POSS-Mo-II)}

POSS-ATZAC obtained earlier ( $2.5 \mathrm{~g}, 1.41 \mathrm{mmol})$ was added to a stirred solution of $\left[\mathrm{Mo}(\mathrm{CO})_{3} \mathrm{Br}_{2}(\mathrm{NCMe})_{2}\right](4.75 \mathrm{~g}, 11.28 \mathrm{mmol})$ in anhydrous ethanol $(50 \mathrm{~mL})$ under nitrogen and the mixture was allowed to stir overnight at $80{ }^{\circ} \mathrm{C}$. The solvent was removed by filtration; the solid that remained (brown powder) was washed three times with anhydrous dichloromethane, and dried, giving $2.4 \mathrm{~g}$ of POSS-Mo-II. Elemental Analysis for $\mathrm{Si}_{8} \mathrm{O}_{34} \mathrm{C}_{54} \mathrm{H}_{72} \mathrm{~N}_{32} \mathrm{Br}_{4} \mathrm{Mo}_{2}$ (2447.48 g/mol): calculated C 26.47\%, N 18.30\%, H 2.94\%, Mo 7.83\%; found C $26.27 \%$, N 18.03\%, H 2.66\%, Mo 7.48\%. IR ( $\mathrm{KBr}$ pellet, $\left.\mathrm{cm}^{-1}\right): \nu$ $(\mathrm{C}-\mathrm{H})=2927, \nu(\mathrm{C} \equiv \mathrm{O})=1938-1839, \nu(\mathrm{C}=\mathrm{O})=1656, \nu$ $(\mathrm{C}=\mathrm{N})=1571, \nu(\mathrm{C}-\mathrm{N})=1450, v_{\text {as }}(\mathrm{Si}-\mathrm{O}-\mathrm{Si})=1110 .{ }^{13} \mathrm{C}$ solid-state NMR (100.61 MHz, ppm): $9.88\left(\mathrm{CH}_{2}-\mathrm{Si}\right), 22.74\left(\mathrm{CH}_{2}-\mathrm{CH}_{2} \mathrm{Si}\right), 48.70$ $\left(\mathrm{CH}_{2}-\mathrm{N}\right), 139.94-149.40$ (aromatic ring), 155.22 (carboxylic acid group). ${ }^{29} \mathrm{Si}$ solid-state NMR (79.48 MHz, (Si-O), ppm): -66.05 (high intensity), -57.45 (low intensity). EDS (Full scale $16064 \mathrm{ct}$ cursor: -0.302 (octs), keV): C, N, O, Br, Si, Mo.

\subsection{Study of immobilization of Mo-I and Mo-II complexes on POSS- ATZAC}

For optimization of the synthesis of two new heterogeneous catalysts, reaction time, thermodynamic effect, and the amount of complexes fixed on the POSS-ATZAc were studied under air atmosphere.

\subsubsection{Equilibrium time of the organometallic complexes}

In this optimization, the POSS-ATZAc was thoroughly mixed into $50 \mathrm{~mL}$ of a solution containing each organometallic complex with concentration of $1.0 \times 10^{-2} \mathrm{M}$ in ethanol and the contact time was varied from 5 to $40 \mathrm{~min}$ at $70 \mathrm{rpm}$.

\subsubsection{Isotherms of immobilization of the molybdenum complexes}

The POSS-ATZAc was immersed in $50 \mathrm{~mL}$ of an ethanol solution containing each complex of concentrations between $1.0 \times 10^{-3}$ to 
$1.0 \times 10^{-2} \mathrm{M}$ under agitation for $25 \mathrm{~min}$ at $25 \pm 0.2^{\circ} \mathrm{C}$. The quantity of the Mo for each complex was determined by ICP-MS.

\subsubsection{Thermodynamic studies of the Mo-I and Mo-II complexes}

The effects of temperature on the immobilization efficiency were investigated for both complexes of molybdenum in the temperature range of $25-65{ }^{\circ} \mathrm{C}$ keeping the concentration of the complexes constant, the dose of adsorbent and the contact time.

\subsection{Chromatographic parameters}

The analyses were obtained through of a GC-MS (Thermo Scientific) using fused silica capillary column. The carrier gas used was the helium with constant pressure mode of $80 \mathrm{KPa}$. The heating ramp of the oven was programmed varying the temperature from 60 to $200^{\circ} \mathrm{C}$ (held for $3 \mathrm{~min}$ ) at a rate of $30^{\circ} \mathrm{C} / \mathrm{min}$. Samples of $1.0 \mu \mathrm{L}$ were injected in a preheated inlet $\left(250{ }^{\circ} \mathrm{C}\right)$ working in the splitless mode. The mass spectrometer was operated in the full scan mode in the range 30-350. To analyse of the conversion percentages, the proportion between diethyl ether and the olefins were calculated.

\subsubsection{Catalytic studies}

POSS-Mo-I and POSS-Mo-II were tested in the epoxidation of 1octene, cyclooctene, limonene, cis-3-hexen-1-ol, trans-3-hexen-1ol and styrene, using tert-butyl hydroperoxide (TBHP) as oxidant at $55{ }^{\circ} \mathrm{C}$ under nitrogen atmosphere [2,6-9] and compared with Mo-I and Mo-II. The reactions were performed in a container with magnetic stirring and under atmosphere of nitrogen (closed system) $[2,6-8]$. In each case, the container was loaded with catalyst/ substrate/oxidant in a ratio of 1:100:200 in mmol\% [2,6-8]. Catalysts: $0.137 \mathrm{mmol}$ of POSS-Mo-I (0.10 g), POSS-Mo-II (0.175 g), Mo-I (0.055 g) and Mo-II (0.064 g); Substrates: $13.70 \mathrm{mmol}$ of 1-Octene $(1.53 \mathrm{~g}, 2.14 \mathrm{~mL})$, cyclooctene $(1.51 \mathrm{~g}, 1.78 \mathrm{~mL}),(\mathrm{S})$-limonene $(1.86 \mathrm{~g}$, $2.20 \mathrm{~mL}$ ), cis-3-hexen-1-ol (1.37 g, $1.61 \mathrm{~mL})$, trans-3-hexen-1-ol $(1.37 \mathrm{~g}, 1.67 \mathrm{~mL})$ and styrene $(1.42 \mathrm{~g}, 1.56 \mathrm{~mL})$; dibutyl ether (internal standard) the same amount in $\mathrm{mmoL}$ of each olefin was used and dichloromethane $\left(\mathrm{CH}_{2} \mathrm{Cl}_{2}\right)$; Oxidant: $27.40 \mathrm{mmol}$ of TBHP (5.0-6.0 $\mathrm{M}$ in decane) (2.47 g, $2.65 \mathrm{~mL}$ ).

The progresses of the reactions were monitored by GC-MS analysis. The reactions were initiated with the addition of the oxidant agent (TBHP). Samples were taken every 20 min during the first $1 \mathrm{~h}$ and then after $2,4,6,8$, and $24 \mathrm{~h}$ of reaction. To disable the oxidant agent, manganese dioxide was added in each collected sample. The resulting suspensions were separated by filtration and an aliquot of the supernatant was injected into the GC-MS. The conversion of each substrate was evaluated by formation of their respective epoxides in a GC-MS using the previously developed methods. Epoxidation test without a metal catalyst was investigated and no catalytic activity was observed [2,6-9].

\section{Results and discussion}

\subsection{POSS-ATZAC- $\left[\mathrm{Mo}\left(\eta^{3}-\mathrm{C}_{3} \mathrm{H}_{5}\right) \mathrm{Br}(\mathrm{CO})_{2}\right]$ (POSS-Mo-I) and POSS- ATZAC- $\left[\mathrm{Mo}(\mathrm{CO})_{3} \mathrm{Br}_{2}\right]$ (POSS-Mo-II) as heterogeneous catalysts}

[3-chloropropyl]-silsesquioxane (POSS-PrCl) precursor was firstly prepared by the hydrolysis of 3-chloropropyltriethoxysilane (CPTES) in methanol under acidic conditions. Next, the POSS-Cl was functionalized subsequently with ATC in a molar ratio of 1:16 resulting in a new functionalized-POSS, abbreviated as POSSATZAc. This new silsesquioxane was functionalized with two types of complexes of $\mathrm{Mo}^{2+}$ according to the optimizations performed in Section 2.3.1 to 2.3.3. The syntheses of the catalysts are shown in Scheme 1.

Based on the nitrogen elemental analysis the density of the organofunctionalization was calculated giving a value of $4.45 \mathrm{mmol}$ of (3-amino-1,2,4-triazole-5-carboxylic acid)propyl groups per gram of material POSS-ATZAc, confirming that eight (3-amino1,2,4-triazole-5-carboxylic acid)propyl arms are linked to silsesquioxane core. The value of $13.15 \%$ of Mo suggests that four molybdenum units are bound to the POSS-ATZAc- $\left[\mathrm{Mo}\left(\eta^{3}-\mathrm{C}_{3} \mathrm{H}_{5}\right)\right.$ $\mathrm{Br}(\mathrm{CO})_{2}$ ] (POSS-Mo-I), whereas the value of $7.48 \%$ confirming that only two molybdenum units are bound to the POSS-ATZAc[Mo(CO) $\left.{ }_{3} \mathrm{Br}_{2}\right]$ (POSS-Mo-II).

In the FTIR of POSS-ATZAc the presence of the carbonyl band $(C=O)$ suggests that the reaction between the propyl chloride arm and ATZAc ligand occurred by $\mathrm{NH}_{2}$ group, once the amine localized in the ring has a greater stability [6,7,10-13]. The FTIR of the POSSMo-I and POSS-Mo-II exhibits additionally the band $\mathrm{C} \equiv \mathrm{O}$ proving the coordination of the complexes $\left[\mathrm{Mo}(\mathrm{CO})_{2}\right]$ and $\left[\mathrm{Mo}(\mathrm{CO})_{3}\right]$ on the POSS-ATZAc. The presences of these bands are in agreement with the literature $[1,4-7]$.

${ }^{13} \mathrm{C}$ NMR of the POSS-ATZAc shows a shift of the first three peaks when compared to POSS-PrCl precursor material [14-16]. This displacement is related to the functionalization reaction with 3amino-1,2,4-triazole-5-carboxylic acid (ATZAc). The others peaks appear due to incorporation of 3-amino-1,2,4-triazole-5-carboxylic acid, these signals are characteristic of ATZAc groups present in the structure, confirming the modifying the surface of the support. After the reaction with $\left[\mathrm{Mo}\left(\eta^{3}-\mathrm{C}_{3} \mathrm{H}_{5}\right) \mathrm{Br}(\mathrm{CO})_{2}(\mathrm{NCMe})_{2}\right]$ complex, the FTIR of the POSS-ATZAC-[ $\left.\mathrm{Mo}\left(\eta^{3}-\mathrm{C}_{3} \mathrm{H}_{5}\right) \mathrm{Br}(\mathrm{CO})_{2}\right]$ (POSS-Mo-I) displays three peak at over than its POSS-ATZAc precursor material. These peaks may be concerning to the allyl groups, indicating the incorporation of the complex on the functionalized-POSS [6]. On the other hand, the resonance peak of the carbonyl groups of the complex of the POSS-ATZAc- $\left[\mathrm{Mo}(\mathrm{CO})_{3} \mathrm{Br}_{2}\right]$ catalyst are not apparent due to the absence of allyl groups $[6,17]$.

The signals observed in the ${ }^{29} \mathrm{Si}$ NMR spectra of the synthesized compounds seem to indicate octa-substituted structures of the POSS with closed cage, which were confirmed by elemental analyses of $\mathrm{C}, \mathrm{H}$ and $\mathrm{N}$. On the other hand, the possibility of occurrence in much smaller percentages of isomer structures or cage expansion products such as deca- and dodecahedral silsesquioxane gages is not excluded $[18,19]$.

Scanning electron micrographs (SEM) were performed in each steps of preparation of the heterogeneous catalysts in order to check their different morphologies. The SEM images of heterogeneous catalysts POSS-Mo-I and POSS-Mo-II are shown in Fig. $1 \mathrm{~A}$ and $B$ respectively.

As can be seen, the images of the heterogeneous catalysts (Fig. 1A and B) present an agglomerate surface [20]. This can be beneficial when dealing with heterogeneous catalysts, since would facilitate their separation and recycling.

In addition, the crystallinity of these silsesquioxane-based compounds was evaluated using powder X-ray diffraction (XRD) techniques.

According to Fig. 2A, the X-ray diffractogram shows that the POSS-PrCl precursor material has high crystallinity, confirming its octahedral cage [18]. After the substitution with ATZAc molecules, the material acquires an amorphous nature (Fig. 2B) [21].

After the reaction with the complexes $\left[\mathrm{Mo}\left(\eta^{3}-\mathrm{C}_{3} \mathrm{H}_{5}\right)\right.$ $\left.\mathrm{Br}(\mathrm{CO})_{2}(\mathrm{NCMe})_{2}\right]$ and $\left[\mathrm{Mo}(\mathrm{CO})_{3} \mathrm{Br}_{2}(\mathrm{NCMe})_{2}\right]$ the X-ray spectra exhibited two major peaks at $9.54^{\circ}$ and $21.96^{\circ}$ (Fig. 2C) for POSSMo-I and at $9.36^{\circ}$ and $21.480^{\circ}$ (Fig. 2D) for POSS-Mo-II catalysts. The appearances of the second peak for both catalysts confirm the incorporation of organometallic complexes on the surface of the POSS-ATZAC.

The TGA curves of the POSS-Mo-I and POSS-Mo-II catalysts in Fig. $3 \mathrm{~A}$ and $3 \mathrm{~B}$ shows that the first mass loss occurs until $100{ }^{\circ} \mathrm{C}$ concerning the loss of physisorbed water [22] with mass loss of 


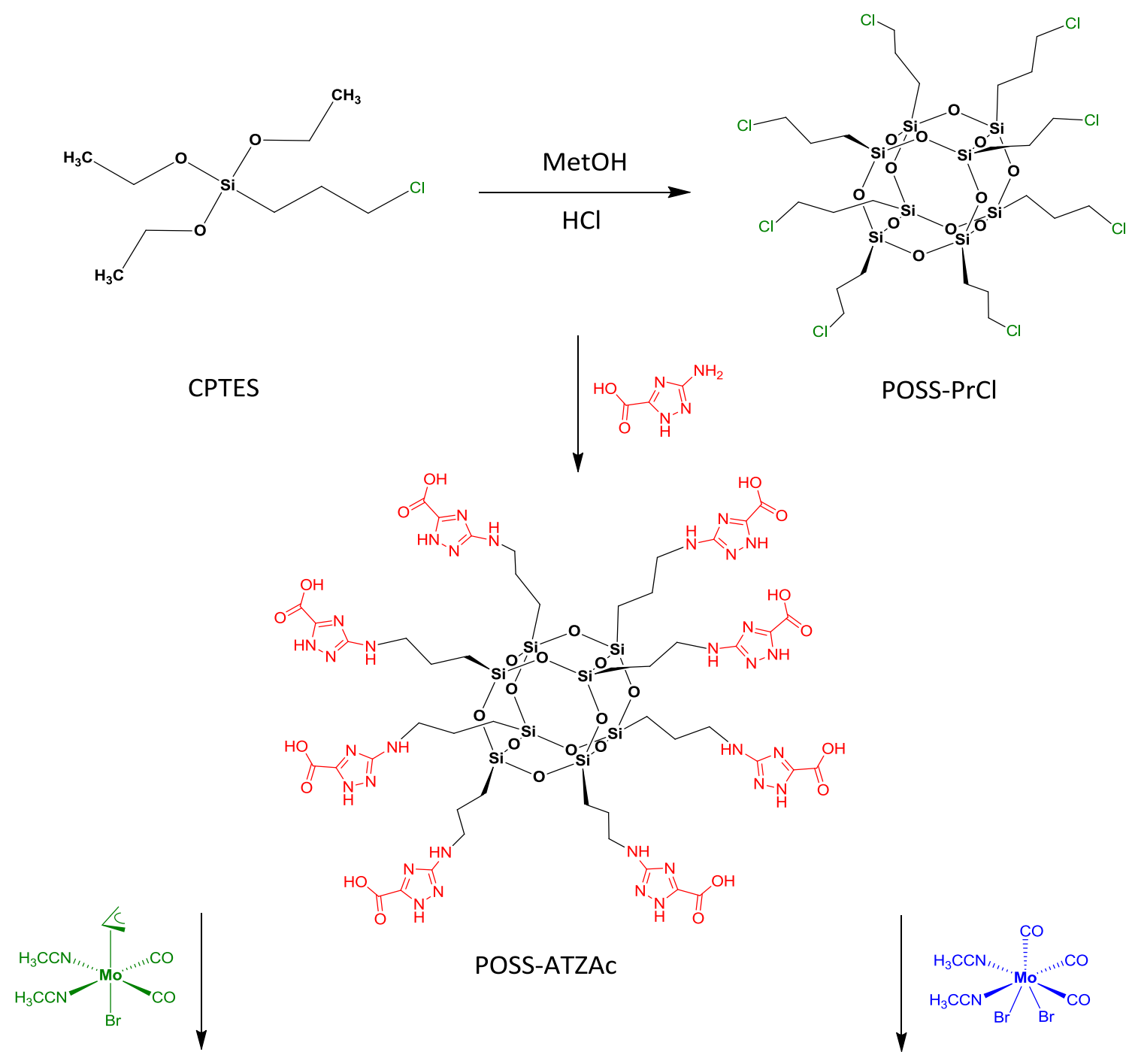

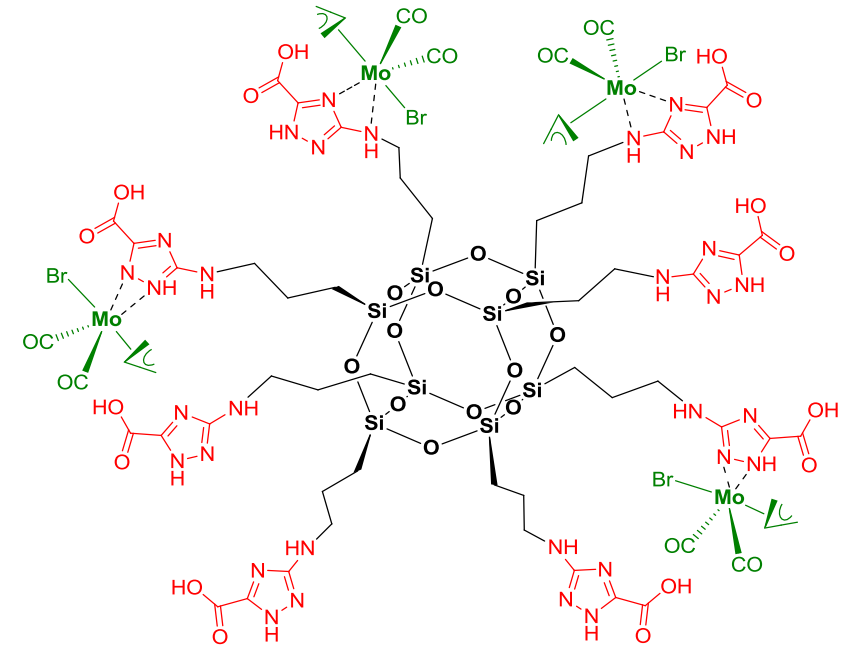

POSS-ATZAC-[Mo( $\left.\left.\mathrm{n}^{3}-\mathrm{C}_{3} \mathrm{H}_{5}\right) \mathrm{Br}(\mathrm{CO})_{2}\right]$

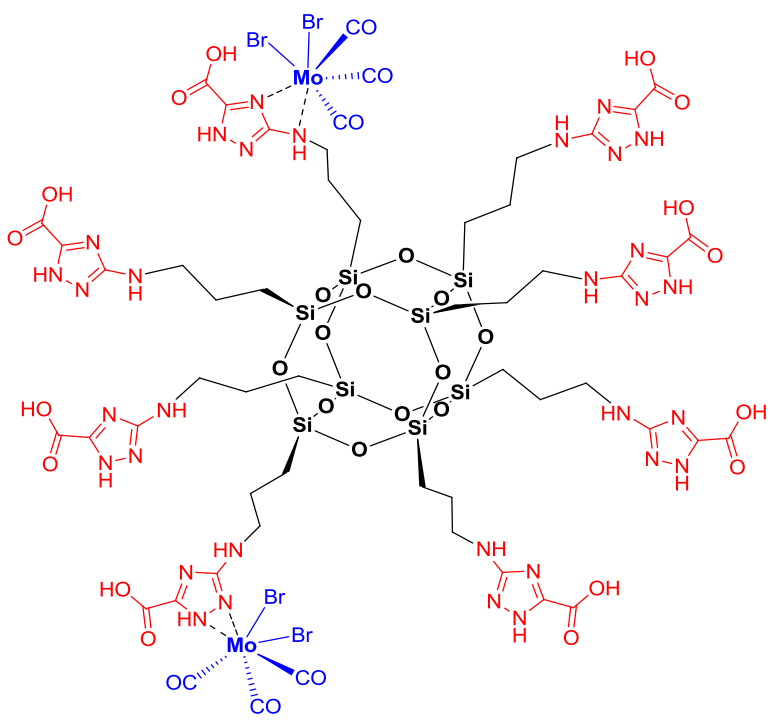

POSS-ATZAC-[Mo(CO) $\left.{ }_{3} \mathrm{Br}_{2}\right]$

Scheme 1. Synthesis of the POSS-ATZAc- $\left[\mathrm{Mo}\left(\eta^{3}-\mathrm{C}_{3} \mathrm{H}_{5}\right) \mathrm{Br}(\mathrm{CO})_{2}\right]$ and POSS-ATZAc- $\left[\mathrm{Mo}(\mathrm{CO})_{3} \mathrm{Br}_{2}\right]$. 

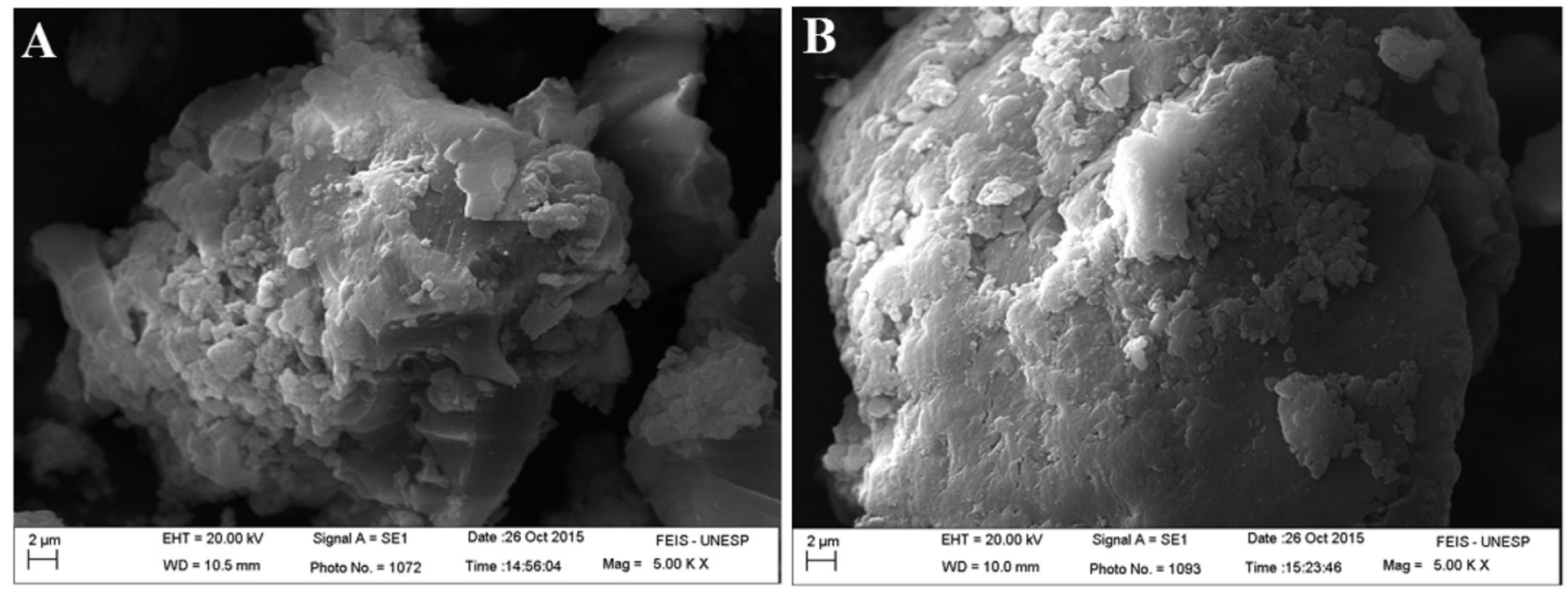

Fig. 1. SEM images of the heterogeneous catalysts POSS-Mo-I (A) and POSS-Mo-II (B).
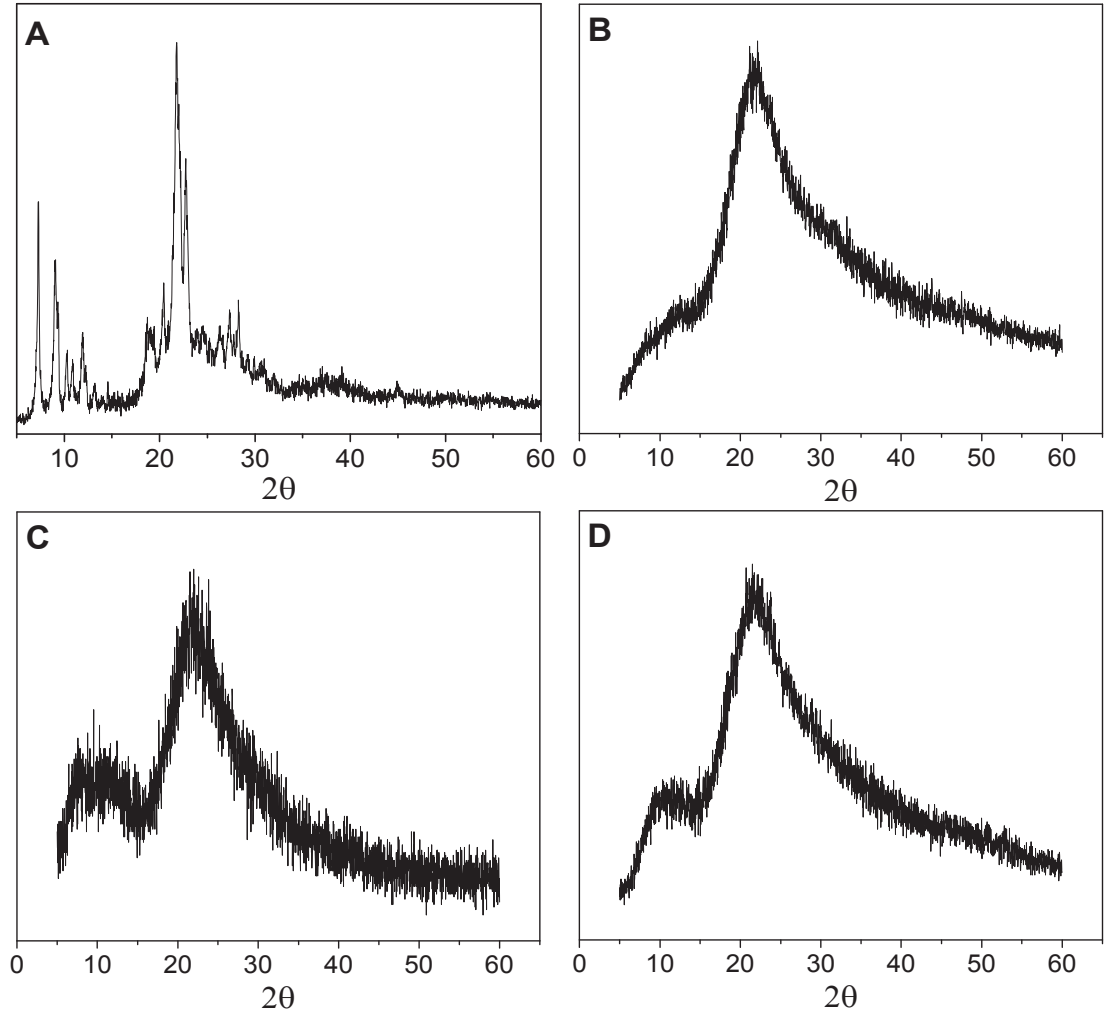

Fig. 2. X-ray diffractograms of the POSS-PrCl (A), POSS-ATZAc (B), POSS-Mo-I (C) and POSS-Mo-II (D).

6.22\% for POSS-Mo-I and $4.18 \%$ for POSS-Mo-II.

The second mass loss of the heterogeneous catalysts POSS-Mo-I and POSS-Mo-II are initiated from $100{ }^{\circ} \mathrm{C}$ to about $470{ }^{\circ} \mathrm{C}$ and refers the decomposition of the 3-amino-1,2,4-triazole-5-carboxylic acid layer [22]. At this stage, the values of $34.23 \%$ for POSS-Mo-I and $38.28 \%$ for POSS-Mo-II show that the eight vertices of the POSS were functionalized with ATZAc molecules. The third mass loss occurs from $470{ }^{\circ} \mathrm{C}$ to about $550^{\circ} \mathrm{C}$. For heterogeneous catalysts are associated with the degradation of the propyl chain together with the organic groups of molybdenum complexes. The amount of mass loss for POSS-Mo-I and POSS-Mo-II was 24.94 and $24.34 \%$ respectively. The thermal stability indicated that both catalysts could be applied under the temperature of about $200^{\circ} \mathrm{C}$.

\subsection{Study of immobilization}

Immobilization experiments such as adsorbent dosage, equilibrium time and immobilization isotherm have been studied to optimize the syntheses process of the two new catalysts. The adsorbent dosage on the immobilization of Mo-I and Mo-II in ethanol solution was investigated and the results were shown in Fig. 4A. As can be seen, the amount of $\left[\mathrm{Mo}\left(\eta^{3}-\mathrm{C}_{3} \mathrm{H}_{5}\right)\right.$ 

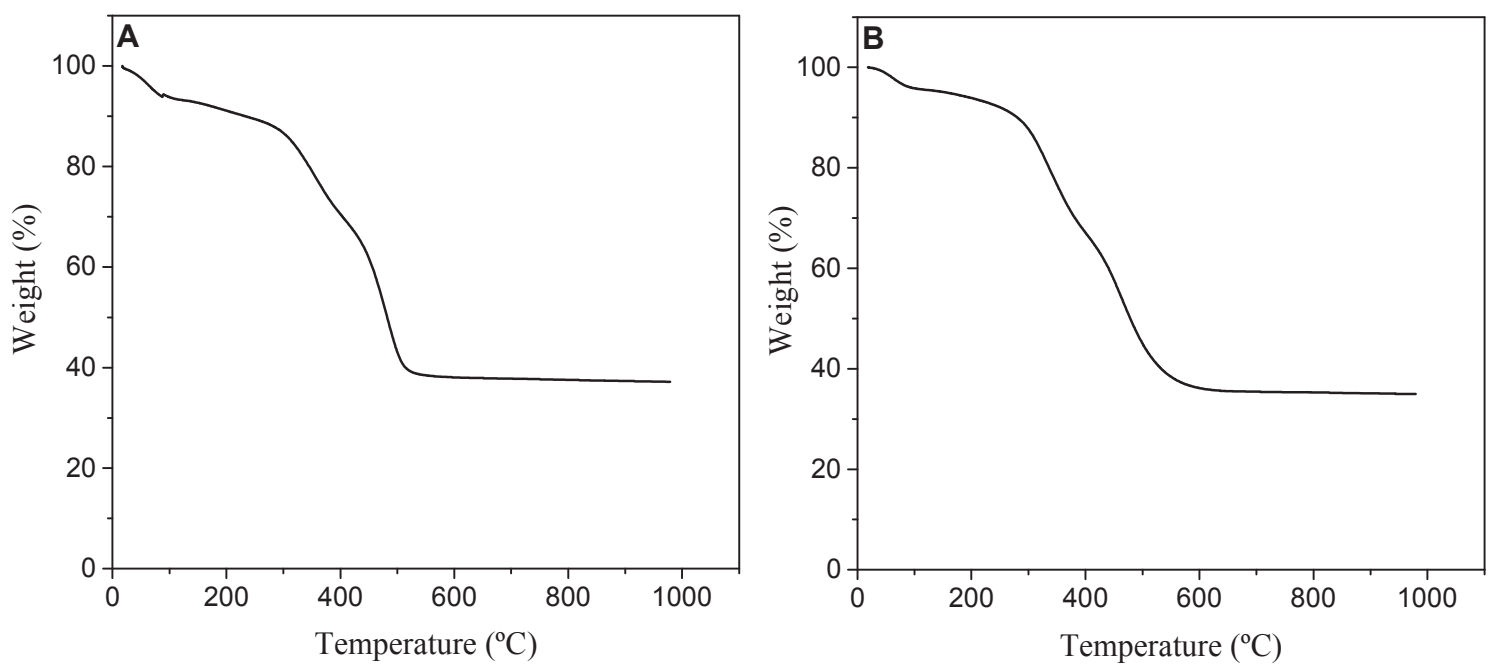

Fig. 3. Thermogravimetric curves of the POSS-Mo-I (A) and POSS-Mo-II (B) under air atmosphere.
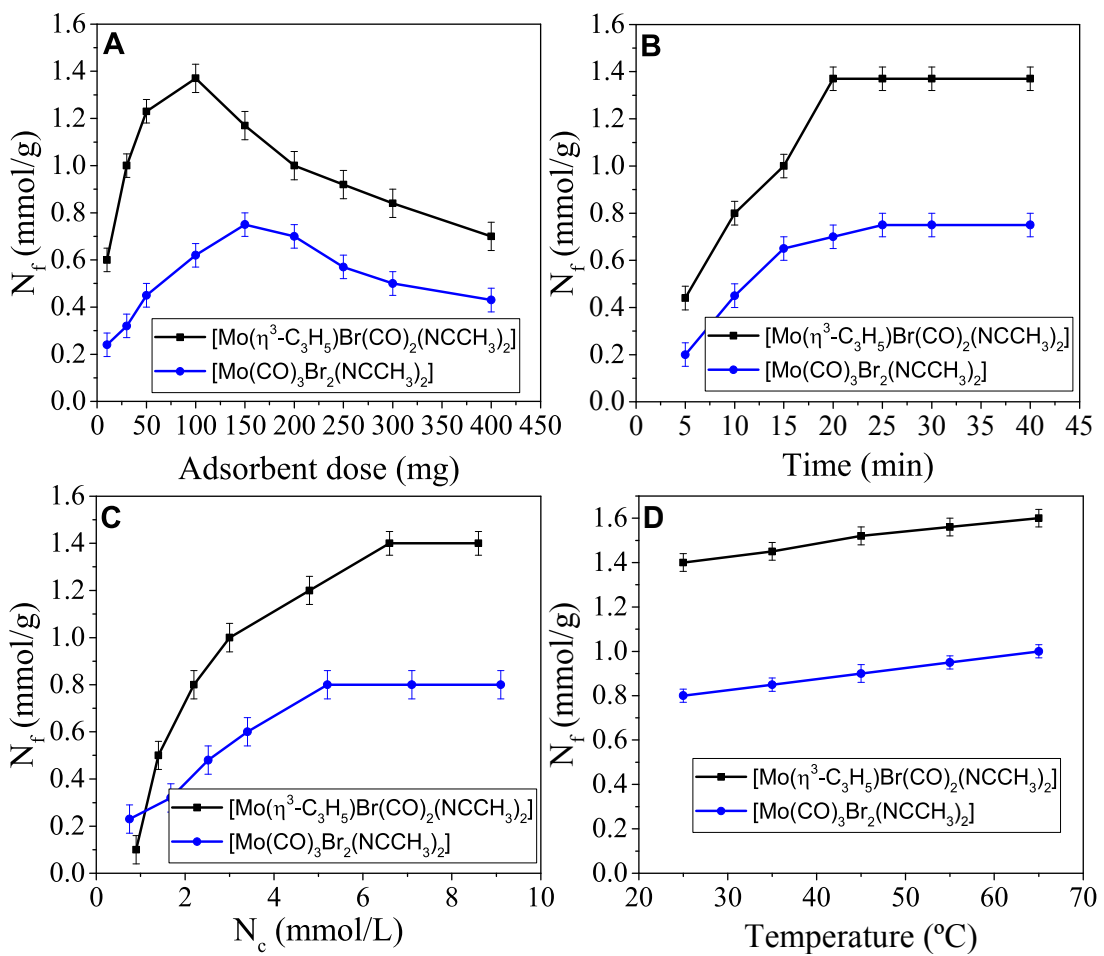

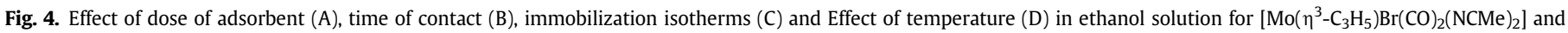
$\left[\mathrm{Mo}(\mathrm{CO})_{3} \mathrm{Br}_{2}(\mathrm{NCMe})_{2}\right]$ using POSS-ATZAC.

$\mathrm{Br}(\mathrm{CO})_{2}(\mathrm{NCMe})_{2}$ ] organometallic complex uptake increases from $0.60 \mathrm{mmol} / \mathrm{g}$ with $10 \mathrm{mg}$ adsorbent up to $1.37 \mathrm{mmol} / \mathrm{g}$ with $100 \mathrm{mg}$ adsorbent and from $0.24 \mathrm{mmol} / \mathrm{g}$ with $10 \mathrm{mg}$ adsorbent up to $0.75 \mathrm{mmol} / \mathrm{g}$ with $150 \mathrm{mg}$ adsorbent for $\left[\mathrm{Mo}(\mathrm{CO})_{3} \mathrm{Br}_{2}(\mathrm{NCMe})_{2}\right]$ complex. This phenomenon was likely due to increased numbers of vacant adsorption sites and increased surface area availability [23-27]. When the amounts of adsorbents were increased to 100 and $150 \mathrm{mg}$ for $\left[\mathrm{Mo}\left(\eta^{3}-\mathrm{C}_{3} \mathrm{H}_{5}\right) \mathrm{Br}(\mathrm{CO})_{2}(\mathrm{NCMe})_{2}\right]$ and $\left[\mathrm{Mo}(\mathrm{CO})_{3} \mathrm{Br}_{2}(\mathrm{NCMe})_{2}\right]$ complexes, the adsorption amounts reached maximums. On the other hand, the immobilization capacity decreased as the adsorbent dosage increased from 100/150 mg due to reduced available surface area and reduced unoccupied active sites.

Furthermore, large doses might result in adsorbent aggregation [24]. Similar results have been reported in the literature [23-26].

Fig. $4 \mathrm{~B}$ shows the effects of contact time on the immobilization of POSS-ATZAc, for the complexes $\left[\mathrm{Mo}\left(\eta^{3}-\mathrm{C}_{3} \mathrm{H}_{5}\right) \mathrm{Br}(\mathrm{CO})_{2}(\mathrm{NCMe})_{2}\right]$ and $\left[\mathrm{Mo}(\mathrm{CO})_{3} \mathrm{Br}_{2}(\mathrm{NCMe})_{2}\right]$ at $25{ }^{\circ} \mathrm{C}$ in ethanol solution. As can be seen, the equilibrium time necessary for the immobilization of the complex $\left[\mathrm{Mo}\left(\eta^{3}-\mathrm{C}_{3} \mathrm{H}_{5}\right) \mathrm{Br}(\mathrm{CO})_{2}(\mathrm{NCMe})_{2}\right]$ was $20 \mathrm{~min}$ and $25 \mathrm{~min}$ for $\left[\mathrm{Mo}(\mathrm{CO})_{3} \mathrm{Br}_{2}(\mathrm{NCMe})_{2}\right]$.

The contact time has significant importance in immobilization studies. The rapid immobilization of the complexes and the equilibrium in a short period indicates the effectiveness of the support 
(POSS-ATZAC).

To investigate the immobilization capacity (Fig. 4C), a concentration range of both complexes in ethanol solutions were shaken at $25{ }^{\circ} \mathrm{C}$. The maximum value for $\left[\mathrm{Mo}\left(\eta^{3}-\mathrm{C}_{3} \mathrm{H}_{5}\right) \mathrm{Br}(\mathrm{CO})_{2}(\mathrm{NCMe})_{2}\right]$ using POSS-ATZAC was $1.40 \mathrm{mmol} \mathrm{g}^{-1}$ and $0.80 \mathrm{mmol} \mathrm{g}^{-1}$ for $\left[\mathrm{Mo}(\mathrm{CO})_{3} \mathrm{Br}_{2}(\mathrm{NCMe})_{2}\right]$.

Additionally, the thermodynamic study was carried out to verify the stability of the organometallic complex on the support.

The effect of the temperature on the immobilization experiments were performed at five different temperatures $(25,35,45,55$ and $65{ }^{\circ} \mathrm{C}$ ). In Fig. 4D, the immobilization process was favored by the increasing of temperature, which demonstrates that, the immobilization of the complexes is endothermic [28].

\subsubsection{Applications of isotherm models}

From Fig. 4C and B it was possible to apply the isotherm and kinetics models [29-31].

Langmuir and pseudo-second-order model are the best ones to describe the immobilization data of both complexes.

The theoretical data of the models that best fit the experimental data are listed in Table 1.

The Langmuir model emphasizes that the immobilization of the molybdenum complex $\left(\left[\mathrm{Mo}(\mathrm{CO})_{3} \mathrm{Br}_{2}(\mathrm{NCMe})_{2}\right]\right)$ was in monolayers. It was also verified that the value of $R_{L}$ was smaller than 1 demonstrating that the immobilization of the complex was favorable [29,30].

The parameter $n$ greater than 1 reflects an immobilization in multi-layered (heterogeneous) of the organometallic complex $\left[\mathrm{Mo}\left(\eta^{3}-\mathrm{C}_{3} \mathrm{H}_{5}\right) \mathrm{Br}(\mathrm{CO})_{2}(\mathrm{NCMe})_{2}\right][32]$.

The $E$ value obtained from the D-R model [33] for immobilization of the complexes were superior than $8 \mathrm{~kJ} / \mathrm{mol}^{-1}$, in which indicates that the immobilizations of the complexes were achieved by chemisorption.

Pseudo-second order model [31] was the most appropriate to define the kinetic data for both complexes.

The negative and positive values of $\Delta G, \Delta H$ and $\Delta S$ show a spontaneous nature, an endothermic process and an increased randomness for both complexes, respectively [31-33]. The temperatures of $25,35,45$ and $55^{\circ} \mathrm{C}$ showed the same behavior.

\section{Activity catalytic}

The activities of POSS-Mo-I, POSS-Mo-II, Mo-I and Mo-II as catalytic precursors for the epoxidation of olefins were investigated. Fig. 5 shows the epoxidation kinetics of the 1-octene, cyclooctene, (S)-limonene, cis-3-hexen-1-ol, trans-3-hexen-1-ol and styrene, using tert-butyl hydroperoxide (TBHP) as oxidant. Fig. 5A shows the epoxidation of each olefin by POSS-Mo-I, in which the maximum conversion rate (conversion time of the olefin to an epoxide) was achieved in a short period of time, i.e. $2 \mathrm{~h}$ for 1 -oct and S-lim, $4 \mathrm{~h}$ for Cy8 and Sty. However, cis-3 and trans-3 require a period of $6 \mathrm{~h}$.

In contrast, the maximum conversion rate for Mo-I (Fig. 5B) was of $4 \mathrm{~h}$ for 1-oct, cis-3 and trans-3, and $2 \mathrm{~h}$ for Cy8, S-lim and Sty. As can be seen, the POSS-Mo-I has only one maximum conversion rate better than Mo-I for the 1-oct olefin, while that the others olefins have a better rate in the presence of the homogeneous catalyst MoI.

The catalysts POSS-Mo-II and Mo-II (Fig. 5C and D) do not exhibit catalytic activity for the most olefins, except for the styrene (Sty) and cyclooctene (Cy8). The maximum conversion rates for both catalysts were of $2 \mathrm{~h}$ for Cy8 and Sty.

Though the necessary period to produce the active species is different in each occasion, similar catalytic species are possibly formed $[6,7]$.

Therefore, the results accessible in Table 2 show that the heterogeneous catalysts in question have a conversion and TOF slightly lower but it in general very similar to homogeneous catalysts. This is due that homogeneous catalysts have advantages over the heterogeneous, in particular greater selectivity and yield [8,34].

Nevertheless, the facility in which the heterogeneous processes products are separated and recycled, make these preferred by industry [8]. The four substrates, cyclooctene, cis-3-hexen-1-ol, trans3-hexen-1-ol and styrene are selectively oxidized to their respective epoxide without formation of diols for all catalysts (heterogeneous and homogeneous).

However, in the oxidation of 1-octene, two products are detected and referred to as 1-octanal and 1,2-epoxyoctane (Table 3). POSS-Mo-I has a high selectivity for formation of 1,2epoxyoctane, $92 \%$ versus $8 \%$ for the formation of 1 -octanal. On the other hand, Mo-I decreases the selectivity for $90 \%$ in epoxy against $10 \%$ for 1 -octanal.

No catalytic activity was detected for the POSS-Mo-II and Mo-II catalysts in the epoxidation of 1-octene, (S)-limonene, cis-3-hexen1-ol and trans-3-hexen-1-ol.

It is known that the conversions and TOF significantly depend on the organometallic complex and the nature of the substrate, and also that the allyl complexes are more active than those of type MoII $[6,7,17]$.

The single detected signal was in the epoxidation of the (S)limonene using Mo-II, which showed a conversion (5\%) and TOF very low.

The epoxidation of (S)-limonene results in the formation of several products (Table 3) and six of them were detected by GC-MS: Isomers of $(+)$-limonene-1,2-epoxide (Z-lim-Epox and E-lim-Epox), isomers of cyclohexen-1-ol-2-methyl-5-(1-methylethenyl) (Z-lim$\mathrm{OH}$ and E-lim-OH), (1S,2S,4R) -(+)-Limonene-1,2-diol $\left(\lim (\mathrm{OH})_{2}\right)$ and dipentene dioxide (dioxide) $[6,35]$.

(S)-limonene has a good conversion and TOF and as can be seen, there is a strong selectivity for oxidation of the double bond between carbons, yielding the Z-lim-Epox, E-lim-Epox and dioxide isomers.

Table 1

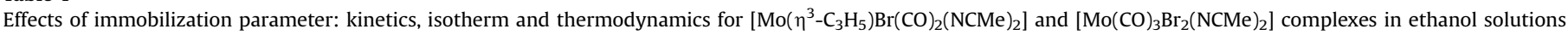
onto POSS-ATZAc.

\begin{tabular}{|c|c|c|c|c|c|c|c|c|c|}
\hline \multirow{2}{*}{$\frac{\left[\mathrm{Mo}\left(\eta^{3}-\mathrm{C}_{3} \mathrm{H}_{5}\right) \mathrm{Br}(\mathrm{CO})_{2}(\mathrm{NCMe})_{2}\right]}{\mathrm{N}_{\mathrm{f}}^{\exp } \mathrm{mmol} / \mathrm{g}}$} & \multicolumn{3}{|l|}{ Langmuir model } & \multicolumn{3}{|c|}{ Pseudo-second-order model } & \multicolumn{3}{|c|}{ Thermodynamic parameters $^{\mathrm{a}}$} \\
\hline & $\mathrm{N}_{\mathrm{f}}^{\max }(\mathrm{mmol} / \mathrm{g})$ & $\mathrm{R}_{\mathrm{L}}(\mathrm{L} / \mathrm{mmol})$ & $\mathrm{R}^{2}$ & $\mathrm{~N}_{\mathrm{f}}^{\max }(\mathrm{mmol} / \mathrm{g})$ & $\mathrm{K}_{2}\left(\min ^{-1}\right)$ & $\mathrm{R}^{2}$ & $\Delta \mathrm{G}(\mathrm{KJ} / \mathrm{mol})$ & $\Delta \mathrm{S}\left(\mathrm{J} / \mathrm{mol} \mathrm{k}^{-1}\right)$ & $\Delta \mathrm{H}(\mathrm{KJ} / \mathrm{mol})$ \\
\hline 1.40 & 1.42 & 0.006 & 0.998 & 1.36 & 8.548 & 0.999 & -33.716 & 99.857 & 35.362 \\
\hline$\left[\mathrm{Mo}(\mathrm{CO})_{3} \mathrm{Br}_{2}(\mathrm{NCMe})_{2}\right]$ & \multicolumn{3}{|c|}{ Langmuir model } & \multicolumn{3}{|c|}{ Pseudo-second-order model } & \multicolumn{3}{|c|}{ Thermodynamic parameters ${ }^{\mathrm{a}}$} \\
\hline $\mathrm{N}_{\mathrm{f}}^{\exp } \mathrm{mmol} / \mathrm{g}$ & $\mathrm{N}_{\mathrm{f}}^{\max }(\mathrm{mmol} / \mathrm{g})$ & $\mathrm{R}_{\mathrm{L}}(\mathrm{L} / \mathrm{mmol})$ & $\mathrm{R}^{2}$ & $\mathrm{~N}_{\mathrm{f}}^{\max }(\mathrm{mmol} / \mathrm{g})$ & $\mathrm{K}_{2}\left(\min ^{-1}\right)$ & $\mathrm{R}^{2}$ & $\Delta \mathrm{G}(\mathrm{KJ} / \mathrm{mol})$ & $\Delta \mathrm{S}\left(\mathrm{J} / \mathrm{mol} \mathrm{k}^{-1}\right)$ & $\Delta \mathrm{H}(\mathrm{KJ} / \mathrm{mol})$ \\
\hline 0.80 & 0.78 & 0.015 & 0.996 & 0.71 & 5.741 & 0.995 & -31.326 & 92.855 & 58.327 \\
\hline
\end{tabular}

a Temperature $=65^{\circ} \mathrm{C}$. 

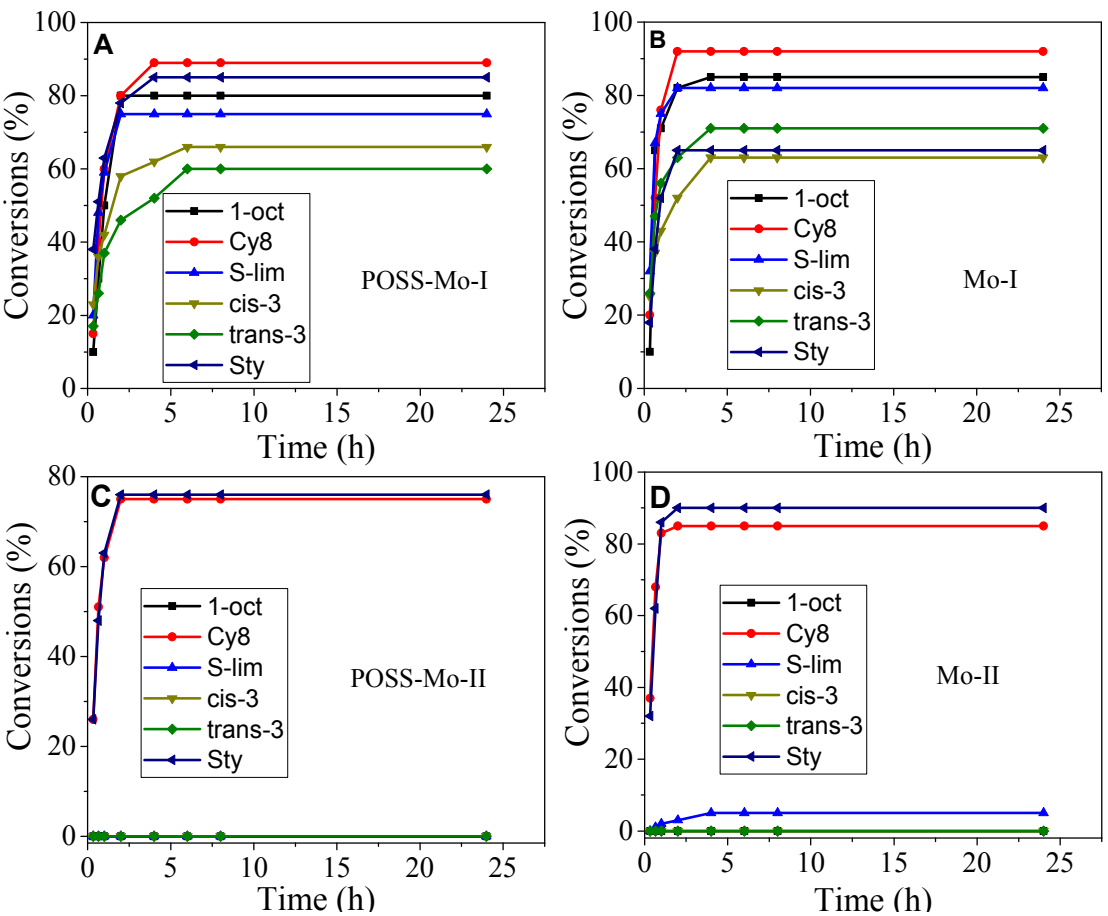

Fig. 5. Epoxidation kinetics of each olefin using heterogeneous and homogeneous catalysts.

Table 2

Conversions and Turnover Frequencies (TOF) for epoxidation of olefins in the presence of TBHP.

\begin{tabular}{|c|c|c|c|}
\hline Catalytic precursor & Substrate & Conversion $^{\mathrm{a}}(\%)$ & $\mathrm{TOF}^{\mathrm{b}}$ \\
\hline POSS-Mo-I & 1-octene & 90 & 152 \\
\hline Mo-I & & 85 & 176 \\
\hline POSS-Mo-II & & 0 & 0 \\
\hline Mo-II & & 0 & 0 \\
\hline POSS-Mo-I & cyclooctene & 89 & 166 \\
\hline Mo-I & & 92 & 172 \\
\hline POSS-Mo-II & & 75 & 117 \\
\hline Mo-II & & 85 & 123 \\
\hline POSS-Mo-I & (S)-limonene & 75 & 149 \\
\hline Mo-I & & 82 & 158 \\
\hline POSS-Mo-II & & 0 & 0 \\
\hline Mo-II & & 5 & 10 \\
\hline POSS-Mo-I & cis $-3^{c}$ & 66 & 134 \\
\hline Mo-I & & 63 & 147 \\
\hline POSS-Mo-II & & 0 & 0 \\
\hline Mo-II & & 0 & 0 \\
\hline POSS-Mo-I & Trans $-3^{\mathrm{d}}$ & 60 & 129 \\
\hline Mo-I & & 71 & 137 \\
\hline POSS-Mo-II & & 0 & 0 \\
\hline Mo-II & & 0 & 0 \\
\hline POSS-Mo-I & styrene & 85 & 130 \\
\hline Mo-I & & 65 & 142 \\
\hline POSS-Mo-II & & 76 & 80 \\
\hline Mo-II & & 90 & 76 \\
\hline
\end{tabular}

a Conversion at $24 \mathrm{~h}$.

b In units of mol (mol of $\mathrm{Mo})^{-1} \mathrm{~h}^{-1}$.

c Cis-3-hexen-1-ol.

d Trans-3-hexen-1-ol.

POSS-Mo-I shows selectivity for epoxide of $87 \%$ whereas that the Mo-I increase this percentage to $95 \%$.

Already, the Mo-II catalyst has a selectivity for epoxide of $100 \%$ (Z-lim-Epox and E-lim-Epox), but the conversion is 5\%.

In the present work, the differences of reactivity between POSSMo-I and POSS-Mo-II catalysts may be associated with the metal coordination sphere and nature of the ligands.

On the other hand, the unexpected better performance of the supported catalyst (POSS-Mo-I) as compared to homogeneous catalyst (Mo-I) in the cases of the 1-octene, cis-3 and styrene conversions can be attributed, at least partly, to its characteristic of being a nanosized catalyst.

Table 4 shows the comparison with other type of catalysts in the epoxidation of olefins. As can be seen, our catalysts have similar conversions or better than other types of Mo-catalysts.

\section{Leaching studies}

Molybdenum leaching studies were also performed by reusing the recovered POSS-Mo-I and POSS-Mo-II in five consecutive reaction cycles [17,39-41]. Before each reuse the solids were separated from the reaction solution, washed with dichloromethane and dried at $50{ }^{\circ} \mathrm{C}$. The catalytic activity decreased slightly from the first to the second cycle, but afterwards tended to remain constant for the POSS-Mo-I and POSS-Mo-II (Table 5).

ICP-MS analysis was used to determine the percentage of molybdenum leached out into the liquid mixture during reactions. The Mo loading of the $\left[\mathrm{Mo}\left(\eta^{3}-\mathrm{C}_{3} \mathrm{H}_{5}\right) \mathrm{Br}(\mathrm{CO})_{2}(\mathrm{NCMe})_{2}\right]$ complex after five reaction cycles is at least $99 \%$ of the starting value for the POSS-MoI, whereas for POSS-Mo-II, the molybdenum loading of the $\left[\mathrm{Mo}(\mathrm{CO})_{3} \mathrm{Br}_{2}(\mathrm{NCMe})_{2}\right]$ complex was $98.3 \%$. The leaching of some weakly anchored molybdenum complex present in the original catalyst may account for the initial low loss of activity for both catalysts. Table 5 also shows the selectivity to epoxycyclooctane for the POSS-Mo-I and POSS-Mo-II until the fifth cycle and, as shown, the selectivity for both catalysts was $100 \%$ in all cycles [42]. Also, the catalytic behavior of the separated liquid was tested by addition of fresh olefin to the filtrates after each cycle. The oxidation reaction under the same reaction conditions as when the catalyst was utilized showed that the found results are the equivalent as blank experiments. 
Table 3

Selectivity in the oxidation of 1-octene and (S)-Limonene.

\begin{tabular}{|c|c|c|c|c|c|c|c|c|c|}
\hline Catalyst & Subs. $^{\mathrm{a}}$ & 1-Octanal ${ }^{\mathrm{b}}$ & 1,2-Epoxyoctane ${ }^{\mathrm{b}}$ & Z-Lim-Epox ${ }^{\mathrm{b}}$ & E-Lim-Epox ${ }^{\mathrm{b}}$ & Z-Lim-OH ${ }^{\mathrm{b}}$ & E-Lim-OH ${ }^{\mathrm{b}}$ & $\operatorname{Lim}-(\mathrm{OH})_{2}{ }^{\mathrm{b}}$ & Dioxide $^{b}$ \\
\hline POSS-Mo-I & 1-octene & 8 & 92 & & & & & & \\
\hline Mo-I & & 10 & 90 & & & & & & \\
\hline POSS-Mo-II & & 0 & 0 & & & & & & \\
\hline Mo-II & & 0 & 0 & & & & & & \\
\hline POSS-Mo-I & (S)-limonene & & & 52 & 33 & 5 & 2 & 6 & 2 \\
\hline Mo-I & & & & 23 & 68 & 2 & 2 & 1 & 4 \\
\hline POSS-Mo-II & & & & 0 & 0 & 0 & 0 & 0 & 0 \\
\hline Mo-II & & & & 80 & 20 & 0 & 0 & 0 & 0 \\
\hline
\end{tabular}

a Substrate.

b Percentage (\%).

Table 4

Comparison of the conversion capacities with others types of Mo-catalysts.

\begin{tabular}{llll}
\hline Catalysts & Olefins & Conv. & Ref. \\
\hline $\mathrm{Mo}^{(\mathrm{VI})} \mathrm{Cl}_{2} \mathrm{O}_{2}$ Bipy & 1-Octene & 55 & {$[36]$} \\
$\mathrm{Mo}-A F B N P s$ & 1-Octene & 60 & {$[37]$} \\
$\mathrm{Mo-AMP-CuBTC}$ & $1-O c t e n e$ & 62 & {$[38]$} \\
{$\left[\mathrm{MoO}_{2} \mathrm{~L}(\mathrm{EtOH})\right]$} & Cy8/1-oct & $88 / 64$ & {$[39]$} \\
POSS-Mo-I & Cy8/1-oct & $89 / 90$ & Present study \\
POSS-Mo-II & Cy8 & 75 & Present study \\
Mo-I & Cy8/1-oct & $92 / 85$ & Present study \\
Mo-II & Cy8 & 85 & Present study \\
\hline
\end{tabular}

a Conversion (\%).

Table 5

Recycling studies performed over heterogeneous catalysts.

\begin{tabular}{llc}
\hline Catalyst & \multicolumn{2}{c}{ Cyclooctene } \\
\cline { 2 - 3 } POSS-Mo-I & Conversion (\%) & Selectivity to epoxide (\%) \\
\hline $1^{\circ}$ cycle & 89 & $100^{\mathrm{a}}$ \\
$2^{\circ}$ cycle & 80 & $100^{\mathrm{a}}$ \\
$3^{\circ}$ cycle & 80 & $100^{\mathrm{a}}$ \\
$4^{\circ}$ cycle & 79 & $100^{\mathrm{a}}$ \\
$5^{\circ}$ cycle & 79 & $100^{\mathrm{a}}$ \\
\hline Catalyst & & Cyclooctene \\
POSS-Mo-II & Conversion $(\%)$ & Selectivity to epoxide (\%) \\
\hline $1^{\circ}$ cycle & 75 & $100^{\mathrm{a}}$ \\
$2^{\circ}$ cycle & 66 & $100^{\mathrm{a}}$ \\
$3^{\circ}$ cycle & 65 & $100^{\mathrm{a}}$ \\
$4^{\circ}$ cycle & 65 & $100^{\mathrm{a}}$ \\
$5^{\circ}$ cycle & 65 & $100^{\mathrm{a}}$ \\
\hline
\end{tabular}

a Epoxycyclooctane.

\section{Conclusions}

The study of immobilization of the $\left[\mathrm{Mo}\left(\eta^{3}-\mathrm{C}_{3} \mathrm{H}_{5}\right)\right.$ $\left.\mathrm{Br}(\mathrm{CO})_{2}(\mathrm{NCMe})_{2}\right]$ and $\left[\mathrm{Mo}(\mathrm{CO})_{3} \mathrm{Br}_{2}(\mathrm{NCMe})_{2}\right]$ complexes was of essential importance to adjust the synthesis of the catalysts.

The results of the characterization techniques allowed attesting that the syntheses of POSS-Mo-I, POSS-Mo-II, Mo-I and Mo-II catalysts were successful.

After the immobilization of the complexes on the precursor material, no trace of the acetonitrile molecule was observed, proving its lability.

The catalyst with allyl group (POSS-Mo-I) was more effective in the epoxidation of olefins, while the POSS-Mo-II showed no catalytic activity for most substrates.

POSS-Mo-I shows a selectivity for epoxide of $100 \%$ for cyclooctene, cis-3-hexen-1-ol, trans-3-hexen-1-ol and styrene, and 92\% for 1 -octene and $87 \%$ for (S)-limonene.

The new catalysts are shown to have a great catalytic activity in the epoxidation of all olefins studies, but with singular attention to cyclooctene which has $89 \%$ conversion using POSS-Mo-I and to styrene which has 76\% using POSS-Mo-II.

Recycling studies performed over heterogeneous catalysts show that the conversions from the second cycle remain constant and with selectivity to epoxide of $100 \%$ for both catalysts.

The activities of the heterogeneous catalysts were similar to those of the homogeneous catalysts.

\section{Acknowledgements}

Eduardo G. Vieira thanks FAPESP-Fundação de Amparo à Pesquisa do Estado de São Paulo (Grant no 2014/05566-5) for scholarships awarded.

Newton Luiz Dias Filho is grateful for the financial support by the FAPESP-Fundação de Amparo à Pesquisa do Estado de São Paulo (Grant no 2013/24602-0), and the CNPq-Conselho Nacional de Desenvolvimento Científico e Tecnológico (Grant no 306265/20133 and 448168/2014-6).

Newton Luiz Dias Filho and Eduardo G. Vieira acknowledge Professor Enes Furlani Junior, of the Department of plant science, food technology and social economy of Unesp-FEIS by analysis of ICP-MS and GC-MS.

\section{References}

[1] J. Gimenez, C.D. Nunes, P.D. Vaz, A.A. Valente, P. Ferreira, M.J. Calhorda, Heptacoordinate halocarbonyl molybdenum (II) and tungsten (II) complexes as heterogeneous polymerization catalysts, J. Mol. Catal. A-Chem. 256 (2006) $90-98$.

[2] M.S. Saraiva, N.L. Dias Filho, C.D. Nunes, P.D. Vaz, T.G. Nunes, M.J. Calhorda, Activity of Mo (II) allylic complexes supported in MCM-41 as oxidation catalysts precursors, Micropor. Mesopor. Mater 117 (2009) 670-677.

[3] E.G. Vieira, I.V. Soares, N.L. Dias Filho, N.C. da Silva, S.D. Perujo, A.C. Bastos, E.F. Garcia, T.T. Ferreira, L.F. Fraceto, A.H. Rosa, Study on soluble heavy metals with preconcentration by using a new modified oligosilsesquioxane sorbent, J. Hazard. Mater 237-238 (2012) 215-222.

[4] E.G. Vieira, R.O. Silva, E.F. Junior, N.L. Dias Filho, Synthesis, characterization and catalytic application of a new organometallic oligomer based on polyhedral oligomeric silsesquioxane, Appl. Organometal. Chem. (2017) e3722, http://dx.doi.org/10.1002/aoc.3722.

[5] P.K. Baker, S.G. Fraser, E.M. Keys, The synthesis and spectral properties of some highly reactive new seven-coordinate molybdenum (II) and tungsten (II) bisacetonitrile dihalogenotricarbonyl complexes, J. Organomet. Chem. 309 (1986) 319-321.

[6] M.V. Dias, M.S. Saraiva, P. Ferreira, M.J. Calhorda, Catalytic activity of molybdenum (II) complexes in homogeneous and heterogeneous conditions, Organometallics 34 (2015) 1465-1478.

[7] N.L. Dias Filho, F.C.M. Portugal, J.M.F. Nogueira, P. Brandão, V. Félix, P.D. Vaz, C.D. Nunes, L.F. Veiros, M.J.V. de Brito, M.J. Calhorda, An oligosilsesquioxane cage functionalized with Molybdenum (II) organometallic fragments, Organometallics 31 (2012) 4495-4503.

[8] E.G. Vieira, I.V. Soares, N.C. da Silva, S.D. Perujo, D.R. do Carmo, N.L. Dias Filho, Synthesis and characterization of 3-[(thiourea)-propyl]-functionalized silica gel and its application in adsorption and catalysis, New J. Chem. 37 (2013) 1933-1943.

[9] A.C. Gomes, S.M. Bruno, M. Abrantes, C.I.R. Magalhães, I.S. Gonçalves, A.A. Valente, M. Pillinger, Catalytic olefin epoxidation with a carboxylic acidfunctionalized cyclopentadienyl molybdenum tricarbonyl complex, J. Organomet. Chem. 760 (2014) 205-211. 
[10] R.M. Silverstein, F.X. Webster, D.J. Kiemle, Spectrometric Identification of Organic Compounds, 7rd ed, John Wiley \& Sons-Inc, 2005.

[11] B. Zhang, D. Zhou, X. Lv, Y. Xu, Y. Cui, Synthesis of polyaspartic acid/3-amino$1 \mathrm{H}-1,2,4$-triazole-5-carboxylic acid hydrate graft copolymer and evaluation of its corrosion inhibition and scale inhibition performance, Desalination 327 (2013) 32-38.

[12] B. Liu, H.J. Feng, Z.H. Zhang, L. Xu, H. Jiao, A new 3D Cd-triazolate framework obtained from in situ decarboxylication of 5-amino-3-carboxyl-1, 2, 4triazole, J. Mol. Struct. 1098 (2015) 240-245.

[13] P.K. Baker, M.B. Hursthouse, A.I. Karaulov, A.J. Lavery, K.M.A. Malik, D.J. Muldoona, A. Shawcross, Seven-coordinate halocarbonyl complexes of the type $\left[\mathrm{MXY}(\mathrm{CO})_{3}(\mathrm{NCMe})_{2}\right](\mathrm{M}=\mathrm{Mo}, \mathrm{W} ; \mathrm{X}, \mathrm{Y}=$ halide, pseudo halide $)$ as highly versatile starting materials, Chem. Soc. Rev. 27 (1998) 125-132.

[14] M. Dutkiewicz, H. Maciejewski, B. Marciniec, Functionalization of polyhedral oligomeric silsesquioxane (POSS) via nucleophilic substitution, Synthesis 2009 (2009) 2019-2024.

[15] D.R. do Carmo, M.S. Magossi, U.O. Bicalho, D.R. Silvestrini, Synthesis, characterization and thermal properties of silsesquioxane organically modified with 4, 5-Diphenyl-2-Imidazolethiol, Inter. J. Chem. 6 (2014) 22-33.

[16] V. Ervithayasuporn, N. Pornsamutsin, P. Prangyoo, K. Sammawutthichai, T. Jaroentomeechai, C. Phuratc, T. Teerawatananond, One-pot synthesis of halogen exchanged silsesquioxanes: octakis (3-bromopropyl) octasilsesquioxane and octakis (3-iodopropyl) octasilsesquioxane, J. Chem. Soc. Dalton Trans. 42 (2013) 13747-13753.

[17] C.D. Nunes, M. Pillinger, A.A. Valente, J. Rocha, A.D. Lopes, I.S. Gonçalves, Dioxomolybdenum (VI)-Modified Mesoporous MCM-41 and MCM-48 materials for the catalytic epoxidation of olefins, Eur. J. Inorg. Chem. 2003 (2003) 3870-3877.

[18] S. Chimjarn, R. Kunthom, P. Chancharone, R. Sodkhomkhum, Preeyanuch Sangtrirutnugul, Vuthichai Ervithayasuporn, Synthesis of aromatic functionalized cage-rearranged silsesquioxanes $\left(\mathrm{T}_{8}, \mathrm{~T}_{10}\right.$, and $\left.\mathrm{T}_{12}\right)$ via nucleophilic substitution reactions, Dalton Trans. 44 (2015) 916-919.

[19] S. Hanprasit, N. Tungkijanansin, A. Prompawilai, S. Eangpayung, V. Ervithayasuporn, Synthesis and isolation of non-chromophore cage-rearranged silsesquioxanes from base-catalyzed reactions, Dalton Trans. 45 (2016) 16117-16120.

[20] P. Yin, Y. Tian, Z. Wang, R. Qu, X. Liu, Q. Xu, Q. Tang, Synthesis of functionalized silica gel with poly (diethylenetriamine bis (methylene phosphonic acid)) and its adsorption properties of transition metal ions, Mat. Chem. Phys. 129 (2011) $168-175$.

[21] V. Ervithayasuporn, K. Kwanplod, J. Boonmak, S. Youngme, P. Sangtrirutnugul, Homogeneous and heterogeneous catalysts of organopalladium functionalized-polyhedral oligomeric silsesquioxanes for Suzuki-Miyaura reaction, J. Catal. 332 (2015) 62-69.

[22] Y. Niu, R. Qu, H. Chen, L. Mu, X. Liu, T. Wang, Y. Zhang, C. Sun, Synthesis of silica gel supported salicylaldehyde modified PAMAM dendrimers for the effective removal of $\mathrm{Hg}$ (II) from aqueous solution, J. Hazard. Mater 278 (2014) $267-278$.

[23] S. Bao, K. Li, P. Ning, J. Peng, X. Jin, L. Tang, Highly effective removal of mercury and lead ions from wastewater by mercaptoamine-functionalised silicacoated magnetic nano-adsorbents: behaviours and mechanisms, Appl. Surf. Sci. 393 (2017) 457-466.

[24] Y.T. Zhou, H.L. Nie, C.B. White, Z.Y. He, L.M. Zhu, Removal of $\mathrm{Cu}^{2+}$ from aqueous solution by chitosan-coated magnetic nanoparticles modified with $\alpha$ ketoglutaric acid, J. Colloid Interf. Sci. 330 (2009) 29-37.

[25] P. Mondal, C.B. Majumder, B. Mohanty, Effects of adsorbent dose, its particle size and initial arsenic concentration on the removal of arsenic, iron and manganese from simulated ground water by $\mathrm{Fe}^{3+}$ impregnated activated carbon, J. Hazard. Mater 150 (2008) 695-702.

[26] N.D. Tumin, A.L. Chuah, Z. Zawani, S.A. Rashid, Adsorption of copper from aqueous solution by Elais Guineensis kernel activated carbon, J. Eng. Sci Technol. 3 (2008) 180-189.

[27] R. Qu, C. Sun, F. Ma, Z. Cui, Y. Zhang, X. Sun, C. Ji, C. Wang, P. Yin, Adsorption kinetics and equilibrium of copper from ethanol fuel on silica-gel functionalized with amino-terminated dendrimer-like polyamidoamine polymers, Fuel 92 (2012) 204-210.

[28] A. Arkhireeva, J.N. Hay, Synthesis of sub-200 nm silsesquioxane particles using a modified Stöber sol-gel routem, J. Mat. Chem. 13 (2003) 3122-3127.

[29] I.V. Soares, E.G. Vieira, N.L. Dias Filho, A.C. Bastos, N.C. da Silva, E.F. Garcia, L.J.A. Lima, Adsorption of heavy metal ions and epoxidation catalysis using a new polyhedral oligomeric silsesquioxane, Chem. Eng. J. 218 (2013) 405-414.

[30] X. Peng, F. Hu, J. Huang, Y. Wang, H. Dai, Z. Liu, Preparation of a graphitic ordered mesoporous carbon and its application in sorption of ciprofloxacin: kinetics, isotherm, adsorption mechanisms studies, Micropor. Mesopor. Mater 228 (2016) 196-206.

[31] E.G. Vieira, I.V. Soares, N.L. Dias Filho, N.C. da Silva, E.F. Garcia, A.C. Bastos, S.D. Perujo, T.T. Ferreira, A.H. Rosa, L.F. Fraceto, Preconcentration and determination of metal ions from fuel ethanol with a new 2,2'-dipyridylamine bonded silica, J. Colloid Interf. Sci. 391 (2013) 116-124.

[32] S. Halder, A. Mukherjee, K. Ghosh, S. Dey, M. Nandi, P. Roy, Synthesis, characterization and catalytic activities towards epoxidation of olefins of dinuclear copper (II) complexes, J. Mol. Struct. 1101 (2015) 1-7.

[33] E.G. Vieira, I.V. Soares, G. Pires, R.A.V. Ramos, D.R. do Carmo, N.L. Dias Filho, Study on determination and removal of metallic ions from aqueous and alcoholic solutions using a new POSS adsorbent, Chem. Eng. J. 264 (2015) 77-88.

[34] A. Schmidt, N. Grover, T.K. Zimmermann, L. Graser, M. Cokoja, A. Pöthig, F.E. Kühn, Synthesis and characterization of novel cyclopentadienyl molybdenum imidazo [1,5-a] pyridine-3-ylidene complexes and their application in olefin epoxidation catalysis, J. Catal. 319 (2014) 119-126.

[35] E.G. Vieira, R.O. Silva, T.E.A. Frizon, A.G. Dal Bó, N.L. Dias Filho, Syntheses and catalytic activities of new metallodendritic catalysts, New J. Chem. 40 (2016) 9403-9414

[36] H. Martínez, M.F. Cáceres, F. Martínez, E.A Páez-Mozo, S. Valange, N.J. Castellanos, D. Molina, J. Barrault, H. Arzoumanian, Photo-epoxidation of cyclohexene, cyclooctene and 1-octene with molecular oxygen catalyzed by dichloro dioxo-(4, 4'-dicarboxylato-2, 2'-bipyridine) molybdenum (VI) grafted on mesoporous $\mathrm{TiO}_{2}$, J. Mol. Catal. A-Chem. 423 (2016) 248-255.

[37] M. Mirzaee, B. Bahramian, M. Mirebrahimi, Amine-functionalized boehmite nanoparticle-supported molybdenum and vanadium complexes: efficient catalysts for epoxidation of alkenes, Chin. J. Catal. 37 (2016) 1263-1274.

[38] Z. Asgharpour, F. Farzaneh, A. Abbasi, M. Ghiasi, Synthesis, crystal structure and DFT studies of a new dioxomolybdenum (VI) Schiff base complex as an olefin epoxidation catalyst, Polyhedron 101 (2015) 282-289.

[39] S. Abednatanzi, A. Abbasi, M. Masteri-Farahani, Post-synthetic modification of nanoporous $\mathrm{Cu}_{3}(\mathrm{BTC})_{2}$ metal-organic framework via immobilization of a molybdenum complex for selective epoxidation, J. Mol. Catal. A-Chem. 399 (2015) 10-17.

[40] J.C. Alonso, P. Neves, M.J. Pires da Silva, S. Quintal, P.D. Vaz, C. Silva A.A. Valente, P. Ferreira, M.J. Calhorda, V. Felix, M.G.B. Drew, Molybdenum $\eta^{3}$ allyl dicarbonyl complexes as a new class of precursors for highly reactive epoxidation catalysts with tert-butyl hydroperoxide, Organometallics 26 (2007) 5548-5556.

[41] M. Ghorbanloo, R. Bikas, G. Małecki, New molybdenum (VI) complexes with thiazole-hydrazone ligand: preparation, structural characterization, and catalytic applications in olefin epoxidation, Inorg. Chim. Acta 445 (2016) 8-16.

[42] Z. Wang, S. Li, W.J. Teo, Y.T. Poh, J. Zhao, T.S.A. Hor, Molybdenum (0) and tungsten (0) carbonyl N-heterocyclic carbene complexes as catalyst for olefin epoxidation, J. Organomet. Chem. 775 (2015) 188-194. 